\section{REIMPLANTATION OF THE RIGHT INTERNAL THORACIC ARTERY AS A FREE GRAFT INTO THE LEFT IN SITU INTERNAL THORACIC ARTERY (Y PROCEDURE)}

\author{
One-year angiographic \\ results
}

Reimplantation of the right internal thoracic artery, as a free graft, into the left in situ internal thoracic artery (Y procedure) has enabled us to bypass more distant marginal vessels, which was not possible by the bilateral technique alone. This prospective study was aimed at evaluating the clinical state of the patients and the degree of patency of grafts within 16 months of follow-up. All 80 patients who underwent the $Y$ procedure between January 1988 and January 1992 were included. This group represented $10 \%$ of the 840 patients having coronary bypass during the same period. A total of 202 coronary anastomoses were performed in this series. Early postoperative (30 days) complications included three deaths (3.75\%), eight myocardial infarctions $(10 \%)$, one case of phrenic nerve paralysis $(1.25 \%)$, two cases of respiratory failure $(2.5 \%)$, and six wound infections (7.5\%). At 3 months' follow-up, $96 \%$ of patients were free of symptoms. During the follow-up period, four patients died of noncardiac causes (lung, pancreatic, and brain cancer and rupture of an abdominal aortic aneurysm). At 1 year, 71 patients were free of symptoms (97\%). Sixty-one patients underwent coronary angiography between 12 and 24 months. Six patients with peripheral arterial disease were not suitable for coronary angiography, and six refused to be tested. These 12 patients had normal thallium test results in the bypassed area (stress or dipyridamole test). The patency rate of the left internal thoracic artery was $98.3 \%(n=60)$, occlusion rate $1.6 \%(n=1)$, and incidence of threadlike arteries $4.9 \%(n=3)$. Thus the rate of perfect patency was $93.4 \%$. The patency rate of the right internal thoracic artery as a free graft was $93.4 \%(n=57)$, occlusion rate $6.5 \%(n=4)$, and the incidence of threadlike arteries $8 \%$ $(n=5)$. Thus the rate of perfect patency was $85.2 \%$. A total of 169 anastomoses were studied. The rate of patency of the anastomoses to the left anterior descending coronary artery was $96 \%(n=58)$ and the occlusion rate, $4 \%(n=2)$. The patency rate of sequential anastomoses (side to side) to diagonal arteries was $100 \%(n=16)$. Patency rate of anastomoses to obtuse marginal arteries was $95 \%(n=58)$ and the rate of occlusion, $4.9 \%(n=3)$. The patency rate of anastomoses to the posterior descending artery or distal branches of the right coronary artery was $80 \%(n=4 / 5)$. We conclude that the $Y$ procedure is a safe technique with an acceptable morbidity and a good patency rate. This procedure can be used when the in situ technique is not possible because of far-reaching distal marginal coronary arteries. (J THORAC CARDIOVASC SURG 1995;109:1042-8)

J. A. Barra, MD, E. Bezon, MD, J. Mansourati, MD, I. Rukbi, MD, P. Mondine, MD, and Y. Youssef, MD, Brest, France
T he internal thoracic artery (ITA) is the conduit of choice for coronary artery bypass. ${ }^{1-3}$ Long-term advantages of this graft are widely recognized. ${ }^{4-7}$ In selected patients sequential anastomoses, the use of

From the Centre Hospitalier Universitaire de Brest, Service de Chirurgie thoracique, cardiaque et vasculaire, Hôpital Augustin Morvan-29609 Brest Cedex, France.

Read at the Twentieth Annual Meeting of The Western Thoracic Surgical Association, Olympic Valley, Calif., June 22-25, 1994.

Address for reprints: J. A. Barra, MD, Centre Hospitalier Universitaire de Brest, Service de Chirurgic thoracique, cardiaque et vasculaire, Hôpital Augustin Morvan-29609 Brest Cedex, France. two ITAs, and the free graft technique increase the versatility of this conduit. ${ }^{8,9}$ Thus complete revascularization of the left ventricle can be achieved with two ITAs. Unfortunately, complete revascularization is sometime impossible to carry out because the ITAs are too short or marginal coronary arteries too distal. Reimplantation of the right ITA, used as a free graft, into the left in situ ITA was reported as a $\mathrm{Y}$ anastomosis technique ${ }^{10,11}$ or a $\mathrm{T}$ technique. ${ }^{12}$ Distal marginal coronary arteries, even the posterior

Copyright $(\mathcal{C} 1995$ by Mosby-Year Book, Inc. $0022-5223 / 95 \$ 3.00+0 \quad \mathbf{1 2 / 6 / 6 3 0 0 3}$ 
descending artery, can be bypassed with these techniques. ${ }^{11,12}$ Despite the fact that a wide myocardial mass was supplied by the new left ITA trunk, good results were reported with $\mathrm{Y}$ and $\mathrm{T}$ techniques. ${ }^{11,12}$ However, some surgeons are afraid that ITAs are not able to deliver adequate flow to a wide left ventricular mass. ${ }^{13}$ The true value of the reimplantation of the right ITA into the left ITA needs to be assessed. Our study reports the clinical results and ITA patency rate at 1 year of the reimplantation of the right ITA into the left in situ ITA with a Y anastomosis.

\section{Patients and methods}

Population. Eighty consecutive patients who underwent Y reimplantation from January 1988 to January 1992 were included in the study. This group represented $10 \%$ of the 840 patients with coronary disease operated on during the same period in our surgical department.

Sixty-eight patients were male $(85 \%)$. Mean age was 59.27 years (age range 30 to 76 years). Thirty-nine patients $(48.7 \%)$ had at least one myocardial infarction (MI) before the operation. Twenty-five patients $(31.5 \%)$ had unstable angina and five required an emergency operation. Ten patients had diabetes $(12.5 \%)$ and 29 were overweight $(36 \%)$. Four of the patients were having repeat operations.

Preoperative catheterization showed that 60 patients $(75 \%)$ had three-vessel disease, $20(25 \%)$ had two-vessel disease, and $10(12.5 \%)$ had main left coronary artery stenosis. Left ventricular ejection fraction, assessed after an extrasystolic contraction, was less than $35 \%$ in two patients $(2.5 \%)$ and less than $50 \%$ in $11(13.5 \%)$.

Operative technique. Left and right ITA pedicles were harvested as described. ${ }^{14}$ Papaverine solution $(3 \mathrm{ml})$ was gently injected into the unclamped ITA by means of an olive-tipped needle. Each ITA was then distally clamped and kept wrapped for 10 minutes in gauze that was soaked in papaverine. Thus full vasodilatation of the ITA was achieved. Then the right ITA was harvested as a free graft. The reimplantation of the right ITA into the left ITA (Y procedure) could be performed with or without the help of cardiopulmonary bypass according to the hemodynamic condition of the patient. The pleural cavity was opened and the pleura and pericardium were cut toward the phrenic nerve to get a straight path to the ITA pedicle from its origin to the left side of the pulmonary artery. Then the site of the $Y$ anastomosis on the left ITA was chosen as follows. The left ITA was laid over the left ventricle along the left anterior descending artery (LAD). At the crossing level between the ITA pedide and the pulmonary valve, the anastomotic site was marked on the left ITA pedicle with a small clip. A cylindrical pad made of gauze $(5 \mathrm{~cm}$ diameter, $9 \mathrm{~cm}$ long) was placed on the pulmonary artery. With the aid of a retractor thread attached to the pad, the pad was pulled up behind the sternum into the upper part of the mediastinum. The proximal part of the left ITA was laid on the pad. Thus the operative field was well exposed, superficial, and motion-
Table I. Destination of ITA and vein grafts

\begin{tabular}{lcccr}
\hline \multicolumn{1}{c}{ Coronary artery } & Left ITA & Right ITA & Vein graft & Total \\
\hline LAD & 50 & 29 & 1 & 80 \\
Sequential jump grafts & 2 & & & 2 \\
Diagonal & 8 & 20 & 0 & 28 \\
Marginal & 27 & 52 & 5 & 84 \\
Right coronary branch & 0 & 3 & 5 & 8 \\
\hline
\end{tabular}

less. The left ITA was opened at the clip level and the pleural side of the right ITA was anastomosed to the costal side of the left ITA by an end-to-side anastomosis. Two 7-0 running sutures were used. The two ITA pedicles were bound together at the anastomotic site, over $1 \mathrm{~cm}$, with human fibrin glue and two 5-0 Prolene sutures (Ethicon, Inc., Somerville, N.Y.). These precautions prevented pulling, tearing, axial twisting, or kinking of the ITA pedicles and anastomosis. Distal coronary artery anastomoses were then performed after the $\mathrm{Y}$ anastomosis was done.

Myocardial protection was achieved with antegrade cold crystalloid cardioplegia and topical cooling. Myocardial temperatures were kept within $12^{\circ}$ to $15^{\circ} \mathrm{C}$ during the aortic crossclamping time. Two isolation pads were used to prevent excessive cooling of the phrenic nerves.

Marginal coronary anastomoses were performed before the LAD anastomoses. The end-to-side anastomosis had to be at least $8 \mathrm{~mm}$ long. Side-to-side anastomoses were not diamond shaped but were longitudinal, axial, and 5 $\mathrm{mm}$ long. All the anastomoses were done with two 8-0 Prolene running sutures tied onto the lateral side of the anastomosis as previously described. ${ }^{9}$ The ITA wall and coronary artery wall were never touched with surgical tools (no-touch technique). The average time to perform one anastomosis was 20 minutes. The destination of the ITA and type of anastomosis are summarized in Table I. A total of 202 anastomoses were performed (2.52 per patient): 191 with ITAs and 11 with saphenous veins.

Criteria of assessment. Perioperative criteria were as follows: mortality, MI (creatine kinase MB [CK-MB] enzyme $>100 \mathrm{U}$ and/or presence of $\mathrm{Q}$ waves, loss of $\mathrm{R}$ wave in chest leads), phrenic nerve paralysis, respiratory support, wound infection, reoperation for bleeding, reoperation for ITA insufficiency, ${ }^{13}$ and use of intraaortic balloon. At 1 year criteria were as follows: late mortality, MI, clinical status, and angiographic follow-up studies. ITA patency rates are presented in terms of occlusion of one branch of the $\mathrm{Y}$ anastomosis, development of threadlike arteries (string sign, very small ITA diameter), and perfect patency (without occlusion, threadlike artery, or ITA stenosis). Ail anastomoses were studied and assessed as patent or occluded.

The $\chi^{2}$ test was used for statistics and Yates test for small groups.

\section{Results}

Operative mortality. Three patients died (3.7\%). One patient could not be weaned from cardiopulmonary bypass, but the ejection fraction was less 
Table II. Patency rate regarding in situ (left) versus free graft (right) ITA and coronary artery bypassed

\begin{tabular}{clllllc}
\hline $\begin{array}{c}\text { No. of ITA } \\
\text { grafts }\end{array}$ & ITA & CABP & Patent & Occlusion & $\begin{array}{c}\text { Threadlike } \\
\text { artery }\end{array}$ & $\begin{array}{c}\text { Perfect } \\
\text { patency }\end{array}$ \\
\hline 41 & Left & LAD & $40(97.5 \%)$ & $1(2.4 \%)$ & $2(4.8 \%)$ & $38(92.6 \%)$ \\
20 & Left & Marginal & $20(100 \%)$ & 0 & $1(5 \%)$ & $19(95 \%)$ \\
17 & Right & LAD & $17(100 \%)$ & 0 & $2(117 \%)$ & $15(88 \%)$ \\
39 & Right & Marginal & $35(89 \%)$ & $4(10 \%)$ & $3(7 \%)$ & $32(82 \%)$ \\
5 & Right & RCAB & $4(80 \%)$ & $1(20 \%)$ & - & - \\
\hline
\end{tabular}

$I T A$, internal thoracic artery; $C A B P$, coronary artery bypassed; $L A D$, left anterior descending artery; $R C A B$, right coronary artery branch.

than $20 \%$; one died of a major gastric hemorrhage and one had a fatal neurologic stroke.

Postoperative complications. MI was diagnosed in eight patients $(10 \%)$. Three patients had an MI in the grafted area $(4 \%)$ with evidence of $Q$ waves and five $(6 \%)$ in the nongrafted area (CK-MB activity increasing without $\mathrm{Q}$ waves). Despite this, none of the eight patients showed hemodynamic deterioration.

Phrenic nerve paralysis occurred in one patient $(1.25 \%)$ and necessitated ventilatory support for 3 weeks.

Respiratory failure affected two patients and necessitated prolonged ventilatory support ( 3 days and 20 days).

Thoracic wound infection occurred in six patients (7.5\%). Three patients had documented bacterial sternal sepsis. All patients were cured without sequelae.

In this series, no patient required reoperation for postoperative bleeding.

No emergency reoperations were needed for hemodynamic deterioration as a result of ITA insufficiency.

In three patients $(3.7 \%)$ an intraaortic balloon was used to ensure safe weaning from cardiopulmonary bypass.

Average hospital stay was 11 days ( 8 to 15 days) when there was no wound infection or need for ventilatory support.

Results at 1 year. Four patients died during the follow-up period. Causes of death were lung cancer, pancreatic cancer, cerebral tumor, and rupture of an abdominal aneurysm in one patient each.

Seventy-three surviving patients were followed up. Severe hemiplegia developed 2 months after the operation in one patient, and this patient was not evaluated. Thus 72 patients were studied at 1 year. Sixty-nine patients $(95.8 \%)$ were free of angina. Sixty-one patients underwent coronary angiography ( $84 \%$ ) between 12 and 24 months (mean 16 months) after the operation. All the patients who had peri- operative MI underwent angiography. Six patients with severe peripheral arterial disease were not suitable for coronary angiography and six patients refused the procedure. These 12 patients underwent a thallium test at 1 year (stress or dipyridamole test). Results of all thallium tests were within normal limits in the area grafted with the ITA.

The global ITA patency rate of the left ITA was 98.3\% (60 ITAs) and the occlusion rate, $1.6 \%$ (1 ITA). The ITA became threadlike in $4.9 \%$ (3 ITAs). Thus perfect patency was present in $94.4 \%$ of left ITA grafts. The global patency rate of the right ITA as a free graft was $93.4 \%$ (54 ITAs) and the occlusion rate, $6.5 \%$ (4 ITAs). The ITA became threadlike in $8 \%$ (5 ITAs). Thus perfect patency was present in $85.2 \%$ of right ITAs. No significant differences were detected between the left and right ITAs.

Eight ITAs became threadlike arteries. Six of these ITAs $(75 \%)$ were associated with nonsignificant native coronary artery stenosis $(<60 \%$ narrowing). In these cases there was a competitive flow in the native artery and the flow in the ITA was very small.

One hundred sixty-nine anastomoses were studied. The rate of patency of anastomoses to the LAD was $96 \%$ (58 anastomoses) and the rate of occlusion, $4 \%$ ( 2 anastomoses). Patency rate of sequential anastomoses (side to side) was $100 \%$ (16 anastomoses). Anastomosis patency rate to the marginal artery was 95\% (58 anastomoses) and rate of occlusion, $4.9 \%$ (3 anastomoses). Anastomosis patency rate to the posterior descending artery or distal branches of the right coronary artery was $80 \%$ (4 of 5 anastomoses). Table II shows the patency rate of the coronary anastomoses according to the left and the right ITAs used. No statistically significant differences exist between the rates of patency, whatever the combination.

In this series there was no case of occlusion of the two branches of the $Y$ anastomosis in the same patient. Right ITA obliteration led to occlusion of 
the whole right ITA, but left ITA occlusion involved only the distal segment, after the $\mathrm{Y}$ anastomosis, of the left ITA. In this case the right free-graft ITA was supplied by the proximal segment of the left ITA, which was perfectly patient with a good anastomosis.

\section{Discussion}

Green, ${ }^{15}$ Tector, ${ }^{8}$ Mills, ${ }^{16}$ Loop, ${ }^{17}$ Dion, ${ }^{18}$ and their associates increased the versatility of the ITA. They described sequential anastomoses, bilateral ITA anastomoses, and the free-graft technique. Reimplantation of the right ITA as a free graft into the left in situ ITA has been previously described. ${ }^{10-12}$ Good late clinical results were reported by Tector and colleagues, ${ }^{12}$ but in their series the number of angiographic follow-up studies was not significant. In our series all 80 consecutive patients were operated on by the same surgeon, with the same technique, and were included in a prospective follow-up program. Furthermore, $84.2 \%$ of the patients underwent angiographic examination at 1 year. Chocron and coworkers $^{19}$ reported a 6 -month patency rate, but the series is divided into two small groups of patients operated on with two different techniques. Their study emphasized the technical aspect of the $Y$ process: in their first group (34 patients), $\mathrm{Y}$ anastomoses were performed after the distal coronary anastomoses were undertaken, and without the help of the cylindrical pad. The patency rate of the free graft was only $45 \%$ in this first group, but in their second group our technique $^{9}$ was applied (the $\mathrm{Y}$ anastomosis is performed before aortic clamping and with the pad). The patency rate of the free graft in this second group rose to $73 \%$.

Perioperative mortality in our series is similar to that in other series of bilateral ITA grafting. ${ }^{12-18}$ In our series a $10 \%$ MI rate may seem high, but only three patients $(3.5 \%)$ had $\mathrm{Q}$ waves in the grafted area. In five patients there was an isolated increase of CK-MB enzymes. In this latter case it was due more to myocardial damage than to localized MI. In our study we used antegrade crystalloid cardioplegia. Buckberg ${ }^{20}$ reported better myocardial protection with retrograde cold blood cardioplegia. Tector and associates, ${ }^{12}$ in their series of 287 reimplantations of the right ITA into the left ITA with a T anastomosis and retrograde blood cardioplegia, reported a $1 \%$ incidence of MI.

Sternal infection occurred in $7.5 \%$ of the patients, but $36 \%$ of our patients were overweight and four infections occurred in these overweight patients. Obesity increases the risk of sternal infection when the two ITA are used. ${ }^{21}$

Reoperation for ITA insufficiency was not necessary in our series. ITA insufficiency jeopardizes the patient's life and necessitates emergency reoperation to graft a vein distal to the ITA anastomosis involved. ${ }^{13} \mathrm{~A}$ $2 \%$ incidence of ITA insufficiency has been reported in the literature when reimplantation of the right ITA into the left ITA with a T anastomosis is used..$^{12}$ In our study three patients had an MI in the area grafted with the ITA. Maybe this MI could be related to moderate ITA insufficiency, but patients were well without hemodynamic deterioration, cardiac drug support, or reoperation. The risk of ITA spasm can be reduced when the distal segment of the ITA is not used. ${ }^{22}$ The last $2 \mathrm{~cm}$ section of the ITA is muscular. ${ }^{23}$ The $\mathrm{Y}$ technique allows resection of this last $2 \mathrm{~cm}$ segment of the right ITA because of the great gain in length of the right ITA and thus could reduce the risk of spasm of the right ITA.

Global patency rate of the left and right ITAs to the LAD were, respectively, $97.5 \%$ and $100 \%$. However, the incidence of threadlike arteries was $4.8 \%$ and $11.7 \%$. If we consider threadlike arteries to indicate graft failure, perfect patency was $93.4 \%$ and $88 \%$. In the literature, the rate of ITA patency to the LAD at 1 year ${ }^{4,18,24}$ ranged from $92 \%$ to $97 \%$. However, only Bergeron and colleagues ${ }^{24}$ reported an incidence of threadlike arteries. In our series there were no statistically significant differences between left and right ITAs, but there was a tendency for better results with the left ITA. With regard to the $\mathrm{Y}$ technique, if possible the left ITA must be used to revascularize the largest coronary artery, which is generally the LAD.

Loop and coworkers ${ }^{17}$ reported a series of aortacoronary bypasses in which the free ITA graft was used: patency of the LAD was $86 \%$ and that of the other coronary arteries, $78 \%$. Dion and coworkers ${ }^{18}$ reported a $79 \%$ rate of global patency with aortacoronary ITA free grafts. In our series, the rate of perfect patency with the right ITA used as free graft was $88 \%$ on the $\mathrm{LAD}$ and $82 \%$ on the marginal arteries. However, the major advantage of the $\mathrm{Y}$ technique is the increase in the length of the free ITA graft available, because $4 \mathrm{~cm}$ can be saved (the distance between the medial aortic line and the left edge of the pulmonary artery, site of the $\mathrm{Y}$ anastomosis). This gain in length allows the revascularization of far-reaching distal arteries: marginal branches or left ventricular branches of the right coronary artery. 
Our incidence of threadlike arteries seems to be high $(6.8 \%)$. However, in $75 \%$ of the cases of threadlike artery the competitive flow from the native artery can explain the evolution of the ITA. Our data suggest that ITAs are sensitive to competitive flow when the $\mathrm{Y}$ technique is used. Therefore this technique is indicated only when coronary arteries are significantly stenotic $(>70 \%)$. Some studies reported that patency of threadlike arteries could be restored. ${ }^{25,26}$ The flow in these arteries increased when the native coronary stenosis reached $70 \% .^{25,26}$ Thus the development of threadlike arteries cannot be considered as a definitive graft failure, but a careful selection of the stenotic coronary artery may avoid this problem.

Our results with sequential anastomoses are similar to those in other reported series. ${ }^{27-29}$ The length of the ITA available with the $\mathrm{Y}$ anastomosis is essential to enable harmonious curves between sequential anastomoses. This avoids pulling of the ITA pedicle, tearing of the anastomosis, and if fibrin glue is used, any kinking and twisting.

Tector and associates ${ }^{12}$ reported a large series of reimplantations of the right ITA into the left ITA with $\mathrm{T}$ anastomoses. Turbulences and low-pressure surfaces (recirculation areas) on the wall of the outlet $\mathrm{Y}$ branches increased with the angle of the bifurcation. ${ }^{30,31}$ The bifurcation angle of the $Y$ anastomosis is less than 20 degrees and that of the $T$ anastomosis is 90 degrees, so that the $\mathrm{T}$ anastomosis is more turbulent than the $\mathrm{Y}$ anastomosis. Moreover, there is a link between low-pressure surfaces and the development of atheroma at the bifurcation in the arterial system. ${ }^{30,31}$

\section{Conclusion}

The $\mathrm{Y}$ technique can be considered safe. It yields a good patency rate at 1 year with an acceptable mortality and morbidity. The extra length of the right ITA allows distal coronary vessels to be bypassed with the ITA. Inasmuch as the sternal medial line is not crossed by the Y graft, any reoperation would be safer. However, the $\mathrm{Y}$ technique requires skill and is time consuming. The $\mathrm{Y}$ technique is applicable, as indeed is the case in our study, only when in situ bilateral ITAs cannot be used to revascularize distal coronary arteries. Patients must be in good condition and have a long life expectancy.

\section{REFERENCES}

1. Tector AJ, Schmahl TM, Canino VR. The internal mammary artery graft: the best choice for bypass of the diseased left anterior descending coronary artery. Circulation 1983;68(Suppl):II214-7.

2. Grondin CM, Campeau L, Lesperance J, Enjalbert M, Bourassa MG. Comparison of late changes in internal mammary artery and saphenous vein grafts in two consecutive series of patients 10 years after operation. Circulation 1984;70(Suppl):I208-12.

3. Okies JE, Page US, Bigelow JC, Krause AH, Salomon NW. The left internal mammary artery: the graft of choice. Circulation 1984;70(Suppl):I213-21.

4. Lytle BW, Loop FD, Cosgrove DM, Ratliff NB, Easley K, Taylor PC. Long-term (5 to 12 years) serial studies of internal mammary artery and saphenous vein coronary bypass grafts. J THORAC CARDIOVASC SURG 1985;89:248-58.

5. Lytle BW, Loop FD, Thurer RL, Groves LK, Taylor PC, Cosgrove DM. Isolated left anterior descending coronary atherosclerosis: long-term comparison of internal mammary artery and venous autografts. Circulation 1980;61:869-94.

6. Sigh RN, Sosa JA, Green GE. Long-term fate of the internal mammary artery and saphenous vein grafts. $\mathbf{J}$ THORAC CARdiovasc SURG 1983;86:359-63.

7. Tector AJ, Schmahl TM, Janson B, Kallies JR, Johnson G. The internal mammary artery graft: its longevity after coronary bypass. JAMA 1981;246: 2181-3.

8. Tector AJ, Schmahl TM, Canino VR, Kallies JR, Sanfilippo D. The role of the sequential internal mammary artery graft in coronary surgery. Circulation 1984;70(Suppl)1222-5.

9. Barra JA, Mondine P, Mansourati J, et al. Résultats à un an des anastomoses mammaires séquentielles. Cliniques: 120 cas. Angiographies: 71 patients. Ann Chir 1991;45:667-72.

10. Barra JA, Mondine P, Bezon E, Mahlab A, Rukbi I, Braesco J. Revascularisation des artères coronaires. Réimplantation en Y de l'artère mammaire interne droite dans l'artère mammaire interne gauche. Presse Med 1991;20:423-5.

11. Sauvage LR. Extensive myocardial revascularization using only internal thoracic arteries for grafting the anterior descending, circumflex and right systems. In: Meyens WO, ed. CABG update. Part II. Cardiac surgery state of the art reviews. Philadelphia: Hanley and Belfus, 1992;6:397-419.

12. Tector AI, Amundsen S, Schmahl TM, Kress DC, Peter M. Total revascularization with $\mathrm{T}$ grafts. Ann Thorac Surg 1994;57:33-9.

13. Jones EL, Lattouf OM, Weintraub WS. Catastrophic consequences of internal mammary artery hypoperfusion. J Thorac Cardiovasc Surg 1989; 98:902-7.

14. Van Son JAM, Smedts F, Vincent JG, Van Lier HJJ, Kubat $\mathrm{K}$. Comparative anatomic studies of various arterial conduits for myocardial revascularization. $\mathrm{J}$ Thorac Cardiovasc Surg 1990;99:703-7. 
15. Green GE, Sterzer SH, Reppert EH. Coronary arterial bypass grafts. Ann Thorac Surg 1968;5:44350.

16. Mills NL, Bringaze WL. Preparation of the internal mammary artery graft. Which is the best method? J Thorac Cardiovasc Surg 1989;98:73-9.

17. Loop FD, Lytle BW, Cosgrove DM, Golding LAR, Taylor PC, Stewart RW. Free (aorta-coronary) internal mammary artery graft: late results. J THORAC Cardrovasc Surg 1986;92:827-31.

18. Dion R, Etienne PY, Verhelst R, et al. Bilateral mammary grafting: clinical, functional and angiographic assessment in 400 consecutive patients. Eur J Cardiothorac Surg 1993; 7:287-94.

19. Chocron S, Etievent JP, Schiele F, et al. The Y graft: myocardial revascularization with both internal thoracic arteries. J THORAC CARDIOvasC SURG 1994;108: $736-40$.

20. Buckberg GD. Antegrade/retrograde blood cardioplegia to ensure cardioplegic distribution: operative techniques and objectives. J Card Surg 1989;4:21638.

21. Medot M, Fissette J, Limet R. Médiastinites: diagnostic, facteurs de risque et traitement. Ann Chir 1993; 47:752-65.

22. He GW. Contractility of the human internal mammary artery at the distal section increases toward the end: emphasis on not using the end of the internal mammary artery for grafting. J THORAC CARDIOVASC SURG 1993;106:406-11.

23. Kay HR, Korns ME, Flemma RJ, Tector AJ, Lepley D. Atherosclerosis of the internal mammary artery. Ann Thorac Surg 1976;21:504-7.

24. Bergeron P, Simonetti B, Poyen V, et al. Contrôle angiographique précoce des revascularisations coronaires par l'artère mammaire interne. A propos d'une série consécutive et prospective de 180 pontages. Ann Chir 1991;45:82-9.

25. Mondine P, Barra JA, Rukbi I, Braesco J. Reperméabilisation tardive spontanée d'un pontage mammaire interne sur l'artère interventriculaire antérieure. Ann Chir 1990;44:115-6.

26. Dincer B, Barner HB. The "occluded" internal mammary artery graft: restoration of patency after apparent occlusion associated with progression of coronary disease. J Thorac Cardiovasc Surg 1983;85:318-20.

27. Kamath ML, Matysik LS, Schmidt DH, Smith LL. Sequential internal mammary artery grafts: expanded utilization of an ideal conduit. J THORAC CARDIOvaSC SURG 1985;89:163-9.

28. Orszulak TA, Schaff HV, Chesebro JH, Holmes DR Jr. Initial experience with sequential internal mammary artery bypass grafts to the left anterior descending and left anterior descending diagonal coronary arteries. Mayo Clin Proc 1986;61:3-8.

29. Tector AJ, Schmahl TM, Canino VR. Expanding the use of the internal mammary artery to improve pa- tency in coronary artery bypass grafting. J THORAC Cardiovasc Surg 1986;91:9-16.

30. Texon M, Impoarato AM, Helpern M. The role of vascular dynamics in the development of atherosclerosis. JAMA 1965;194:168-72.

31. Lynn NS, Fow VG, Ross LW. Computation of fluiddynamical contributions to atherosclerosis at arterial bifurcations. Biorheology 1972;9:61-6.

\section{Discussion}

Dr. Steve Guyton (Seattle, Wash.). The ITA as a bypass conduit carries a significant relative immunity to the effects of atherosclerosis. The results of studies such as presented here by Professor Barra continue to push us toward increased use of the ITA for complete revascularization. This report advanced our knowledge about the versatility of the ITA and validates the increasing complexity of coronary bypass operations in our attempt to provide long-term benefits to our patients. Professor Barra and his colleagues are to be commended on their excellent results and careful follow-up in this challenging area. The devil is in the details, however.

Meticulous attention to detail is evident in Professor Barra's description of operative technique. Long anastomoses performed in the longitudinal axis of the coronary artery and use of 8-0 suture material contribute significantly to the excellent results these authors have demonstrated with greater than 1 year of angiographic follow-up. The 20-minute average time for a distal anastomosis is made possible by the excellent myocardial preservation techniques now available. Sternal wound problems remain a risk that are inextricably and often unpredictably linked to ITA use. This fact was recently brought home to me by a patient without risk factors and an otherwise unremarkable course in whom infarction of the manubrium occurred after ITA harvesting. Despite some risks, the long-term advantages of ITA grafting are becoming increasingly evident.

Professor Barra, the Y procedure was applied to $10 \%$ of your patients over a 4-year period. You stressed several times that patient selection is essential to its success, as well as to avoiding ITA insufficiency. Can you compare the patients in this study with the other $90 \%$ of your patients having coronary bypass with regard to age, left ventricular function, how many of these received bilateral ITA grafts, and how many received only saphenous grafts?

Dr. Barra. In our practice, about $70 \%$ of the patients received two ITA grafts. We used two ITA grafts in patients up to 70 years of age who were not diabetic and who, occasionally, were obese, although obesity in France is not as severe a problem as in America.

Dr. Guyton. We do know that this $10 \%$ of patients were relatively young with good left ventricular function, but selection criteria are not clearly spelled out. Are there characteristics of the ITAs, the coronary anatomy, or the clinical situation that preclude the use of bilateral ITAs? I reiterate that the devil is in these details.

Dr. Barra. Sometimes we did not use the ITA because of intimal dissection of the artery. In other cases, especially in women, the ITA is very thin. Also, we measure the flow in the ITA, and if it is not adequate (more than 
60 or $70 \mathrm{ml}$ ), we do not use the artery, but this is not frequent. Poor ventricular function does not prevent us from using the ITA. All of our patients, even those 80 years of age, have at least one ITA graft on the LAD. It is very uncommon for us to use only vein grafts-only when the ITA is not suitable.

Dr. Kent W. Jones (Salt Lake City, Utah). I am disturbed by two numbers. One is your $7.5 \%$ rate of mediastinal infection, which is significant. The second is the patency rate of the right ITA free graft. If you include the threadlike arteries, which are really noncontributory to myocardial blood flow, your patency rate at 1 year is only $86 \%$, which to me is not very good. Could you justify those two numbers in using this technique?

Dr. Barra. The right ITA is not as good as the left ITA in terms of 1-year patency rate, and we reserve the left
ITA for the LAD. However, the patency rate of the right ITA to the marginal coronary arteries is significantly better than that of vein grafts. The literature shows only a $65 \%$ to $70 \%$ rate of perfect vein graft patency to the marginal arteries at 1 year, which is very bad and highly significantly lower than our results with the $Y$ technique. The use of two ITAs, in situ or in free grafts with or without the $Y$ technique, is certainly a major improvement in coronary surgery. In our experience there is no significant difference between grafting of the in situ right ITA to the marginal branch and free right ITA grafting used with the $\mathrm{Y}$ technique. Concerning sternal wound infection, all of our patients were cured without sequelae after 25 days (on average) of irrigation and closed aspiration. In young patients under 65 years of age, the benefits of long-term patency compensate for the risk of postoperative wound infection.

\section{Bound volumes available to subscribers}

Bound volumes of THE Journal of THORACIC AND CARDIOvASCULAR SURGERY are available to subscribers (only) for the 1995 issues from the Publisher, at a cost of $\$ 91.00$ for domestic, $\$ 118.77$ for Canadian, and $\$ 111.00$ for international subscribers for Vol. 109 (January-June) and Vol. 110 (July-December). Shipping charges are included. Each bound volume contains a subject and author index and all advertising is removed. Copies are shipped within 60 days after publication of the last issue of the volume. The binding is durable buckram with the JouRnal name, volume number, and year stamped in gold on the spine. Payment must accompany all orders. Contact Mosby-Year Book, Inc., Subscription Services, 11830 Westline Industrial Drive, St. Louis, Missouri 63146-3318, USA; phone 1 (800) 453-4351 or (314) 453-4351.

Subscriptions must be in force to qualify. Bound volumes are not available in place of a regular JouRvaL subseription. 